\title{
Cardiovascular Stability during Off-Pump Coronary Artery Bypass (OPCAB) Surgery- A Comparison between Combined High Thoracic Epidural Anaesthesia (HTEA) with TIVA and TIVA alone
}

\author{
SI Azad ${ }^{1}$, AK Beg ${ }^{1}$, AYFE Chowdhury ${ }^{1}$, UHS Khatun ${ }^{2}$ \\ ${ }^{1}$ Department of Anaesthesiology, NICVD. ${ }^{2}$ Department of Anaesthesiology and ICU, \\ Dhaka Medical College Hospital, Dhaka.
}

Key Word: $C A B G$, $O P C A B$, HTEA, TIVA

\begin{abstract}
:
Background: In Bangladesh, although OPCAB surgery are done, the number of centers are limited and as a result, studies on this subject are also few. Consequently, there are no exclusive data regarding the best anaesthetic technique in the context of superior haemodynamic stability. This study has been undertaken with a view to find out whether a combined HTEA with GA (TIVA) is safe and more efficient in providing overall cardiovascular stability. The common challenges for the cardiac anaesthesiologist during off pump coronary artery surgery (OPCAB) to maintain optimal cardiovascular parameters such as heart rate, blood pressure, CVP and arrhythmias during the different stressful surgical events and multiple cardiac manipulations, providing adequate myocardial protection, are sometimes difficult. This study has been undertaken with a view to find out whether a combined HTEA with TIVA is safe and more efficient in providing overall cardiovascular stability.
\end{abstract}

Method: Sixty patients aged between 40-70 years, without having any coagulopathy disorder, any emergency surgery or left main disease scheduled for CABG on beating heart were enrolled in prospective, randomized observational comparative study. Patients were divided in two groups. In group A patients received TIVA alone and in group B patients received high thoracic epidural anaesthesia with TIVA. The parameters including heart rate, SPO2, CVP, arterial blood pressure , rate pressure product, arrhythmia in ECG, were recorded before induction, during induction, intubation and during different events of the surgery ( skin incision, sternotomy, pericardiotomy, coronary artery anastomosis with graft, sternum closure and wound closure) was recorded.

Result: Significant per-operative mean heart rate changes were observed all the events except at wound closure and during anastomosis with D1/D2 and the mean difference of mean of mean arterial pressure at intubations, skin incision, sternotomy, pericardiotomy, during anastomosis of distal end of the graft with RCA, PDA, LCX and D1/D2 were observed statistically significant $(p<0.05)$. No incidence of different arrhythmia occurred in group $B$, premature ventricular complex $(P V C)$ was statistically significant $(p<0.05)$ between two groups.

Conclusion: HTEA with TIVA appeared to be most comprehensive, allowing for revascularization of any coronary artery, providing good cardiovascular stability during OPCAB.

(Cardiovasc.j. 2010; 2(2) : 163-167)

\section{Introduction:}

During general anaesthesia in cardiothoracic surgery cardiovascular changes may be detrimental in patients with coronary artery diseases due to concomitant increase in myocardial oxygen demand, decrease in oxygen supply, and the possibility of myocardial ischaemia. ${ }^{1-6}$ This is often difficult to achieve optimal cardiovascular stability. During beating-heart surgery, to obtain an adequate exposure of the anastomosis site with restrained cardiac motion; and to protect the myocardium from ischaemia during coronary artery flow interruption, the anaesthetist must be prepared to handle severe haemodynamic alterations, transient deterioration of cardiac pump function, and acute intraoperative

Address of Correspondence : Dr. Md. Saiful Islam Azad, Department of Anaesthesiology, NICVD, Dhaka, Bangladesh. 
myocardial ischaemia. Within the past few years, high thoracic epidural anaesthesia (HTEA) as an adjunct to general anaesthesia (GA) has become more prevalent 3,4 and has been shown to be potentially beneficial in patients with coronary diseases. ${ }^{8}$ Thoracic epidural anaesthesia provides good protection from stress response, 5,6 ensures hemodynamic stability, 5,7 improves distribution of coronary blood flow and reduce demand for oxygen and per operative arrhythmia. 9,10 There may be scanty studies of HTEA with total intravenous anaesthesia were done previously to evaluate the cardiovascular stability during OPCAB surgery. In this study we have tried to evaluate the safe, efficient anaesthetic technique to provide superior cardiovascular stability during OPCAB surgery. The statistical risk of epidural haematoma following TEA is between 1: 150,000 and 1: 1500(95\% confidence) and up to 1: 1000 (99\% confidence).

\section{Aims and Objectives:}

To compare, which one is safe and more efficient during off pump coronary artery by pass surgery (OPCAB) between combined High Thoracic Epidural Anaesthesia (HTEA) with Total intravenous anaesthesia (TIVA) and Total intravenous anaesthesia (TIVA) alone.

\section{Materials and Methods:}

This Prospective, randomized observational comparative study was undertaken about sixty patients aged between 40-70 years of both male and female with physical status-American society of anaesthesiologist (ASA) - I, II, III \& IV and New York Heart Association (NYHA) - I, II, III \& IV, scheduled for OPCAB were included in this study and divided into two groups, thirty in each group and were randomly selected by card sampling methods. Group A patients received TIVA alone and group B patients received high thoracic epidural anaesthesia with TIVA. Patient having left main coronary disease, history of previous cardiac surgery, left ventricular ejection fraction $<35 \%$, contraindications of regional anaesthesia were excluded. Selection of the patients, grouping, entry of name of the patient in the case record form and the written informed consent was taken from all patients on the preoperative day. Pre-medication with oral
Midazolam $7.5 \mathrm{mg}$ was given in the night before surgery. Patients were fasted 6 hours before operation. After transferring the patients into the operation room, standard monitoring (five lead ECG, pulse Oxymetry) was instituted. All patients were pre-oxygenated with $100 \%$ oxygen. With all aseptic precaution intravenous cannulation, radial arterial catheterization and central venous catheterization was established. Epidural catheter was inserted at the level of T1-2 or T2-3 interspaces in the patients of group B . Fifteen minutes before surgery, high thoracic epidural anaesthesia was given in group B patients with $0.25 \%$ Bupivacaine $10 \mathrm{ml}$ bolus followed by $8 \mathrm{ml} /$ $\mathrm{hr}$ through continuous epidural infusion during operative period and general anaesthesia was induced in all patients of both group with fentanyl $10 \mu \mathrm{g} / \mathrm{kg}$ IV , Propofol $1 \mathrm{mg} / \mathrm{kg}$ IV .Tracheal intubations were facilitated by Pancuronium bromide $0.1 \mathrm{mg} / \mathrm{kg}$ and anaesthesia was maintained with Propofol infusion @ 50-100 $\mu \mathrm{g} / \mathrm{kg} /$ min, fentanyl infusion @1-2 $\mu \mathrm{g} / \mathrm{kg} / \mathrm{hr}$, inhalation gas oxygen and air was given. The parameters including heart rate, systolic blood pressure, diastolic and mean blood pressure, SPO2, CVP, rate pressure product, arrhythmia in ECG, before induction, during induction, intubation and during different events of the surgery ( skin incision, sternotomy, pericardiotomy, coronary artery anastomosis with graft, sternum closure and wound closure) were recorded. At the end of the surgery, all patients were transferred to the intensive care unit without extubation and ventilation was maintained by the ventilator. When there were accepted criteria for tracheal extubation, patients were extubated and shifted to the post operative care unit after accepted criteria for discharge from intensive care unit.

\section{Results:}

No significant mean age, weight, height and body surface area (BSA) differences were found between two groups in unpaired t-test.

The per-operative mean heart rate changes at wound closure and during anastomosis with D1/ D2 were not statistically significant $(p>0.05)$ in unpaired t-test and others were statistically significant $(\mathrm{p}<0.05)$ (Figure 1$)$. 


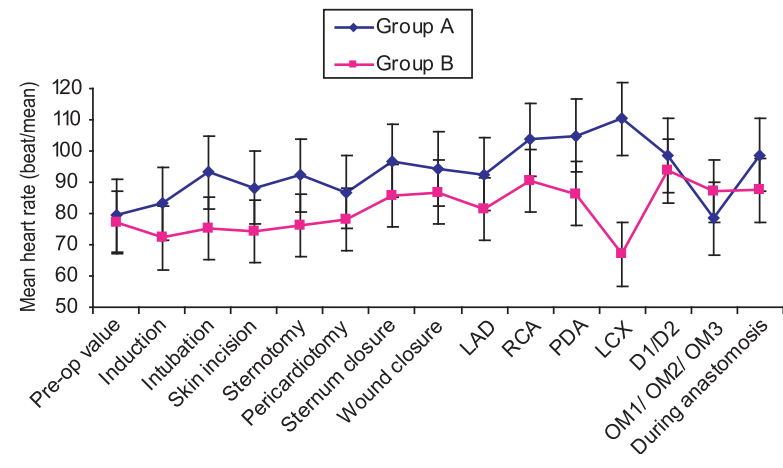

Fig.-1: Line diagram showing per-operative heart rate (beat/min) changes at different times of the study patients.

The Fig.-2 showed per-operative mean arterial systolic pressure changes at different times and found the mean difference of arterial systolic pressure at intubation, skin incision, sternotomy, pericardiotomy, during anastomosis of distal end of the graft with RCA, PDA and D1/D2 were statistically significant $(\mathrm{p}<0.05)$ in unpaired t-test and others were not statistically significant $(p>0.05)$.

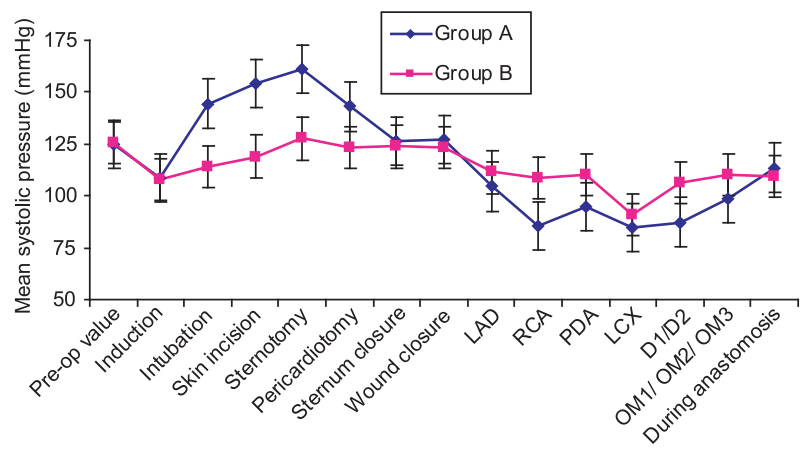

Fig.-2: Line diagram showing per-operative arterial systolic pressure $(\mathrm{mmHg})$ changes at different times of the study patients.

The Fig.-3 showed per-operative mean arterial diastolic pressure changes at different times and found the mean difference of arterial diastolic pressure at intubation, skin incision, sternotomy, during anastomosis of distal end of the graft with RCA, PDA, LCX and D1/D2 were statistically significant $(p<0.05)$ in unpaired t-test and others were not statistically significant $(p>0.05)$.

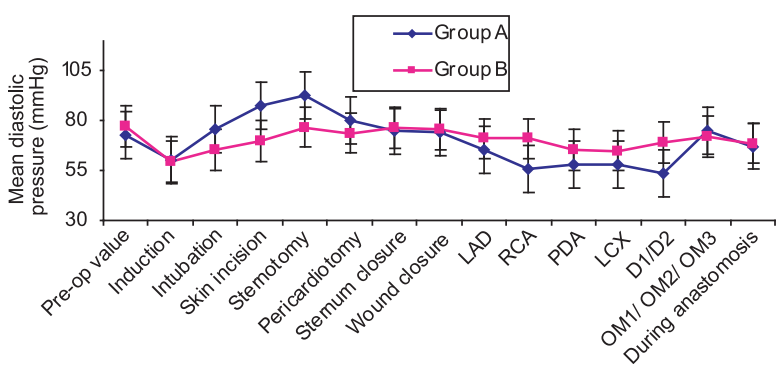

Fig.-3: Line diagram showing per-operative arterial diastolic pressure $(\mathrm{mmHg})$ changes at different times of the study patients

The Fig.-4 showed per-operative mean rate pressure product (RPP) changes at different times and found the mean difference of rate pressure product $(\mathrm{RPP})$ were statistically significant $(\mathrm{p}<0.05)$ in unpaired t-test and except pre-op value.

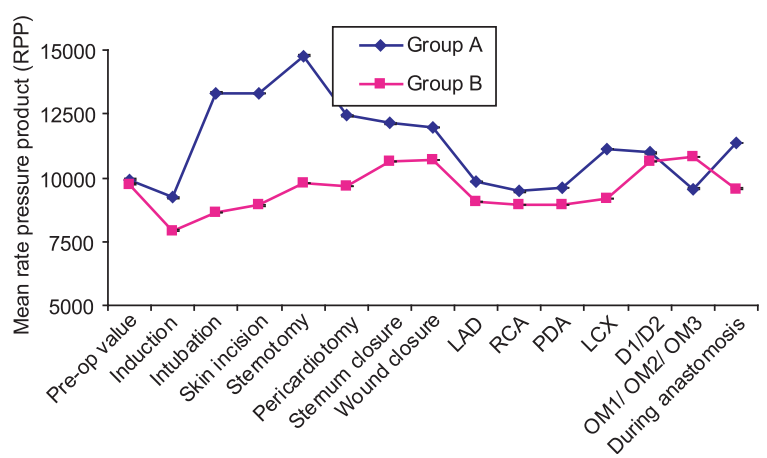

Fig.-4: Line diagram showing per-operative mean rate pressure product (RPP) changes at different times of the study patients.

The per-operative mean of mean arterial pressure changes at intubation, skin incision, sternotomy, pericardiotomy, during anastomosis of distal end of the graft with RCA, PDA, LCX and D1/D2 were statistically significant $(\mathrm{p}<0.05)$ in unpaired t-test and others were not statistically significant $(p>0.05)$

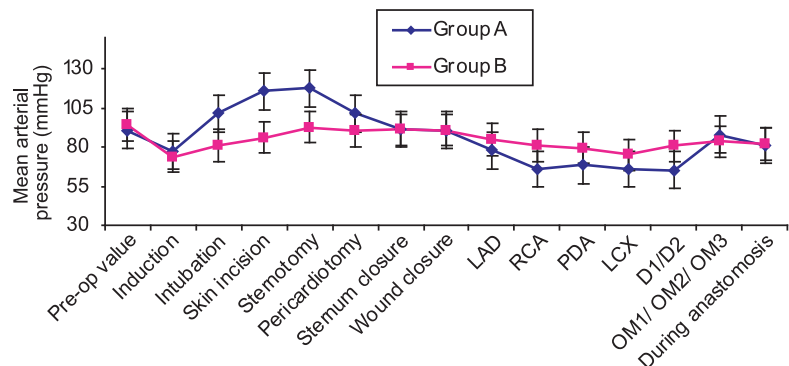

Fig.-5: Line diagram showing per-operative mean of mean arterial pressure $(\mathrm{mmHg})$ changes at different times of the study patients. 
The per-operative mean central venous pressure changes during anastomosis of distal end of the graft with PDA, LCX, D1/D2 and OM1/OM2/OM3 were statistically significant $(\mathrm{p}<0.05)$ in unpaired t-test and others were not statistically significant $(\mathrm{p}>0.05)$.

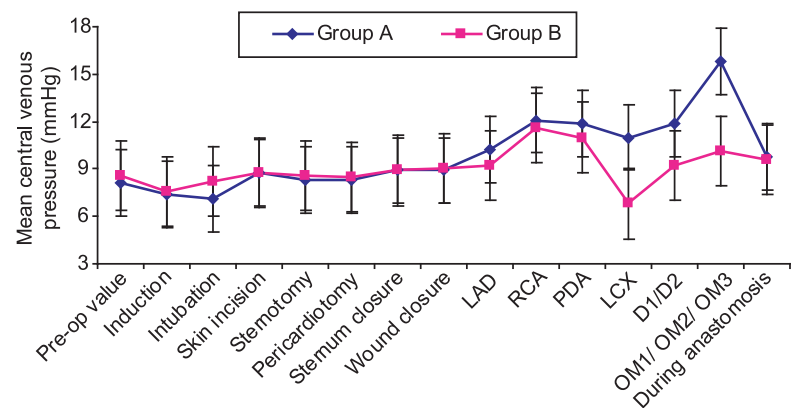

Fig.-6: Line diagram showing per-operative central venous pressure $(\mathrm{mmHg})$ changes at different times of the study patients

\section{Discussion:}

In the current study the male patients was predominant, which is consistent with Kessler et al., Salvi et al. and Scott et al. studies. ${ }^{3,12,13}$ In this study it was observed that per-operative mean heart rate changes at wound closure and during anastomosis of distal end of the graft with D1/D2 were not statistically significant $(p>0.05)$, however rest of others times were significantly $(p<0.05)$ less in group B, which is comparable with other studies. $4,11,13$ In this study it was observed that most of the patients in group B, heart rate was stable in the whole operative period but in group A, intravenous beta-adrenergic blocker (esmolol) was used due to developed tachycardia especially during the performance of anastomosis on the beating heart. It was found in this current study that per-operative mean systolic arterial pressure changes at intubation, skin incision, sternotomy, pericardiotomy, were significantly $(\mathrm{p}<0.05)$ higher in group A but during anastomosis of distal end of the graft with RCA and PDA were significantly $(p<0.05)$ higher in group B which was with in the normal range however others were not statistically significant $(p>0.05)$. Similarly, peroperative mean diastolic arterial pressure changes at intubation, skin incision, sternotomy, were significantly $(p<0.05)$ higher in group A but during anastomosis of distal end of the graft with RCA, PDA, LCX and during anastomosis of distal end of the graft with D1/D2 were significantly $(p<0.05)$ higher in group B and others were almost similar between two groups. It was found in this current study that per-operative mean of mean arterial pressure (MAP) changes at intubation, skin incision, sternotomy, pericardiotomy were significantly $(\mathrm{p}<0.05)$ higher in group A but during anastomosis of distal end of the graft with RCA, PDA, LCX and D1/D2 were significantly $(p<0.05)$ higher in group $\mathrm{B}$ and others were almost similar between two groups. Per operative mean rate pressure product changes at different times was found significantly lower in Group B. Kessler et al. ${ }^{4}$ obtained consistent findings in their study in group B, which is similar with the present study, however in group A the present study found higher with the above study findings before anastomosis but during anastomosis of distal end of the graft with different coronary artery mean of MAP were decline below $70 \mathrm{mmHg}$. Similarly, Salvi et al. 13 reported identical finding in this regard, which is closely support the present study.

Before induction of general anaesthesia no hypotension was observed in both groups but only two in group B was developed hypotension during 15 minutes after giving $0.25 \%$ bupivacaine bolus dose $(10 \mathrm{ml})$ through epidural catheter which was managed by vasoconstrictor (Ephedrine $5 \mathrm{mg}$ intravenous route stat). In this study it was observed that per-operative mean CVP changes at during anastomosis of distal end of the graft with PDA, LCX, D1/D2 and OM1/OM2/OM3 were significantly $(\mathrm{p}<0.05)$ higher in group $\mathrm{A}$ and others were almost consistent between two groups. On the other hand Kessler et al. ${ }^{4}$ and Salvi et al. ${ }^{13}$ have observed identical mean CVP of their patients, which are closely resemble with the present study.

\section{Conclusion:}

Based on the present study results, all anesthetic techniques were equally safe. However, HTEA with TIVA appeared to be most comprehensive, allowing for revascularization of any coronary artery, providing good cardiovascular stability during OPCAB.

\section{References:}

1. Stoelting RK. Circulatory changes during ditrect laryngoscopy and tracheal intubation. Influence of 
duration of laryngoscopy with or without prior lidocaine. Anaesthesiology 1977;47: 381-3.

2. Stone DJ, Gal TJ. Airway management. In: Miller Rd (Ed.) Anaesthesia, $5^{\text {th }}$. New york; Churchill Livingstone Inc; 2000;1444-6.

3. P. Kessler, T. Aybek, Gerd Neidhart, Selami Dogan , Volker Lischke, Dorothee H .Bremerich, et al., Comparison of three anesthetic techniques for Off-pump coronary artery bypass grafting: general anaesthesia, Combined general and high thoracic epidural anaesthesia, or high thoracic epidural anaesthesia alone. Journal of Cardiothoracic and Vascular Anaesthesia 2005;19: 32-39.

4. Goertz AW, Seeling W, Heinrich H, et al., Influence of high thorasic epidural anaesthesia on left ventricular contractility assessed using the end systolic pressure length relationship.Acta Anaesthesiol Scand 1993;37:38133.

5. Blomberg S, Curelaru I, Emanuelsson H, et al., Thoracic epidural anaesthesia in patients with unstable angina pectoris.Eur Heart $J$ 1989;10:437-44.

6. Reiz S, Nath S, Rais O, Effects of thoracic epidural block and prenalterolon coronary vascular resistance and myocardial metabolism in patients with coronary artery disease. Acta Anaesthesiol Scand 1980;24:11.135.

7. Blomberg S, Emanuelsson H, Ricksten SE, Thoracic epidural anaesthesia and central hemodynamics in patients with unstable angina pectoris.Anesthesiology 1990; 73: 840-7.
8. Leim TH, Hasenbos MA, Booij LH, Geilen MJ. Coronary artery bypass grafting using two different anesthetic techniques. Part 2: Postoperative outcome. J Cardiothorac Vase Anesth 1992;6:156-61.

9. Scott NB, Turfrey DJ, Ray DA. Aprospective randomized study of the potential benefits of thoracic epidural anaesthesia and analgesia in patients undergoing coronary artery bypass grafting. Anesth Analg 2001;93(5):28-35.

10. Turfrey DJ, Ray DA, Suteliffe NP, Ramayya P, Kenny GN, Scott NB. Thoracic epidural anaesthesia for Coronary artery bypass graft surgery. Effects on postoperative complications. Anaesthesia 1997;52:10905.

11. RK Kundu, AK Beg, S Hossain, N Haque, Mahafuddoza, A Chowdhury. Comparative study of haemodynamic status and arrhythmia between combined epidural with general anaesthesia and general anaesthesia alone in Off-pump coronary artery bypass (OPCAB) surgery. $J$ Bangladesh Coll Phys Surg 2008;26:116-120.

12. Scott MB, Turfrey DJ, Ray DA. Aprospective randomized study of the potential benefits of thoracic epidural anaesthesia and analgesia in patients undergoing coronary artery bypass grafting. Anesth Analg 2001;93(5):28-35.

13. Salvi L, Sisillo E, Brambillasca C, Juliano G, Salis S and Marino MR. High thoracic epidural anaesthesia for offpump coronary artery by pass surgery. $J$ Cardiothorac Vasc Anesth 2004;18(3):256-62. 